\title{
Evidence for coral range expansion accompanied by reduced diversity of Symbiodinium genotypes
}

\author{
Carsten G. B. Grupstra ${ }^{1,2,3}$ (D) $\cdot$ Rafel Coma ${ }^{4} \cdot$ Marta Ribes $^{2} \cdot$ Karine Posbic Leydet $^{5,6}$ • \\ John Everett Parkinson ${ }^{7,8} \cdot$ Kelly McDonald $^{9}$ Marc Catllà $^{2,4} \cdot$ Christian R. Voolstra $^{3}$ • \\ Michael E. Hellberg ${ }^{5} \cdot$ Mary Alice Coffroth $^{10}$
}

Received: 27 September 2016/Accepted: 2 May 2017/Published online: 15 May 2017

(c) The Author(s) 2017. This article is an open access publication

\begin{abstract}
Zooxanthellate corals are threatened by climate change but may be able to escape increasing temperatures by colonizing higher latitudes. To determine the effect of host range expansion on symbiont genetic diversity, we examined genetic variation among populations of Symbiodinium psygmophilum associated with Oculina patagonica, a range-expanding coral that acquires its symbionts through horizontal transmission. We optimized five microsatellite primer pairs for S. psygmophilum and tested them on Oculina spp. samples from the western North Atlantic and the Mediterranean. We then used them to compare symbiont genotype diversity between an Iberian core and an expansion front population of $O$. patagonica. Only one multilocus $S$. psygmophilum genotype was identified at the expansion front, and it was shared with the core population, which harbored seven multilocus
\end{abstract}

Communicated by Biology Editor Dr. Simon Davy

Electronic supplementary material The online version of this article (doi:10.1007/s00338-017-1589-2) contains supplementary material, which is available to authorized users.

Carsten G. B. Grupstra

cgb.grupstra@gmail.com

1 Institute for Biodiversity and Ecosystem Dynamics, Faculty of Science, University of Amsterdam, Science Park 904, 1098 XH Amsterdam, The Netherlands

2 Institut de Ciències del Mar, ICM-CSIC, Passeig Marítim Barceloneta 37-49, 08003 Barcelona, Spain

3 Red Sea Research Center, Division of Biological and Environmental Science and Engineering (BESE), 4700 King Abdullah University of Science and Technology (KAUST), Thuwal 23955-6900, Saudi Arabia

4 Centre d'Estudis Avançats de Blanes, CEAB-CSIC, Accés Cala Sant Francesc 14, 17300 Girona, Spain genotypes. This pattern suggests that $O$. patagonica range expansion is accompanied by reduced symbiont genetic diversity, possibly due to limited dispersal of symbionts or local selection.

Keywords Oculina patagonica $\cdot$ Symbiodinium psygmophilum $\cdot$ Zooxanthellae $\cdot$ Microsatellites $\cdot$ Climate change $\cdot$ Symbiosis

\section{Introduction}

Tropical coral-reef communities are declining worldwide due to several threats, including rising sea surface temperatures associated with climate change (Wilkinson 2008). However, some corals may be able to escape warming waters by expanding their range to higher latitudes (Precht and Aronson 2004; but see Muir et al. 2015). The ability of some zooxanthellate coral hosts to associate with different Symbiodinium types, or even switch between them, may contribute to acclimatization of the coral

5 Department of Biological Sciences, Louisiana State University, Baton Rouge, LA 70803, USA

6 Biology Department, Syracuse University, Syracuse, NY, USA

7 Department of Biology, Pennsylvania State University, State College, PA, USA

8 Department of Integrative Biology, Oregon State University, Corvallis, OR, USA

9 Department of Biological Sciences, University at Buffalo, Buffalo, NY 14260, USA

10 Graduate Program in Evolution, Ecology and Behavior and Department of Geology, University at Buffalo, Buffalo, NY 14260, USA 
holobiont to newly encountered or changing environmental conditions (e.g., Silverstein et al. 2015), because unique Symbiodinium types exhibit variable tolerance to different environmental regimes (e.g., temperature and light; Thornhill et al. 2008; Hume et al. 2016). Therefore, higher Symbiodinium diversity within coral populations, combined with the ability of hosts to associate with different symbiont types, is expected to result in increased resilience to environmental change (Baskett et al. 2009).

Oculina patagonica is a shallow-water (0-10 m; Serrano et al. 2013) stony coral that reproduces through broadcast spawning and acquires algal symbionts through horizontal transmission (Fine et al. 2001). Symbiodinium psygmophilum (ITS2 type B2, LaJeunesse et al. 2012; cp23S type B224, Santos et al. 2003a) is the primary symbiont associated with $O$. patagonica (Leydet and Hellberg 2016). This coral is rapidly colonizing northern waters along the Mediterranean coast of the Iberian Peninsula (Serrano et al. 2013), providing an excellent opportunity to examine the effect of zooxanthellate coral range expansion on Symbiodinium genetic diversity.

In this study, we first optimized five microsatellite primer sets for $S$. psygmophilum, then used them to compare S. psygmophilum genotypic variation between two distant populations of $O$. patagonica: one population from the demographic core area of its distribution along the Iberian coastline and one in the expansion front.

\section{Methods}

Primers for five microsatellite loci were developed or optimized to examine genotypic diversity of the algal symbiont associated with Oculina, S. psygmophilum LaJeunesse, Parkinson and Reimer, 2012. Oculina samples were obtained from the western North Atlantic and the Mediterranean Sea. Populations of Oculina in the western North Atlantic were originally described as several taxa based on morphology; however, recent genetic data indicate the presence of genetically distinct populations that do not reflect the current morphologically based species classifications (Eytan et al. 2009). For simplicity, we refer to these samples as Oculina spp. Mediterranean Oculina populations consist only of $O$. patagonica de Angelis, 1908, which is genetically distinct from the western Atlantic Oculina spp. populations (Leydet and Hellberg 2015). Oculina spp. samples were acquired by Leydet and Hellberg (2016) from North Carolina $(n=5)$, Daytona Beach, FL $(n=5)$, Cape Florida, FL $(n=4)$, and Panama City, FL $(n=5)$. Oculina patagonica samples were acquired by Leydet and Hellberg (2016) from Italy $(n=2)$, Greece $(n=2)$, Israel $(n=2)$, and Lebanon $(n=2)$. Additional fragments of $O$. patagonica were collected from two Iberian populations: Cabo Cope ( $n=20$; mean depth $1.5 \mathrm{~m}$ ), a "core" Iberian population (Zibrowius and Ramos 1983); and Roca de l'Illot ( $n=20$; mean depth $1.8 \mathrm{~m}$ ), a population from the expansion front (Serrano et al. 2013) approximately $380 \mathrm{~km}$ north of Cabo Cope (Fig. 1). DNA was extracted using the Qiagen DNeasy blood and tissue kit modified for extraction of Symbiodinium DNA by adding a bead-beating step to rupture symbiont cell walls (Coffroth et al. 1992).

The presence of $S$. psygmophilum in all samples was verified using cp23S markers (224 bp fragment size, Santos et al. 2003a). Genotypic diversity of S. psygmophilum was examined using microsatellite loci. A total of 41 primer sets were screened, of which 22 were designed from the S. psygmophilum transcriptome (Parkinson et al. 2016) using PRIMER3 (Koressaar and Remm 2007; Untergasser et al. 2012). Microsatellite repeats were identified using SciRoKo (Kofler et al. 2007). Other primers tested were previously developed for Symbiodinium ITS2 types B1 and B7 (Santos et al. 2003b; Pettay and LaJeunesse 2007; Andras et al. 2009). Optimization yielded five primer sets (Table 1) with 2-9 alleles per locus (Electronic supplementary material, ESM, Table S1). All forward primers had an M13 sequence (5'-CAC GAC GTT GTA AAA CGA CG-3') at the $5^{\prime}$ end for attachment of IRdye (Li-Cor Biotechnology). PCR reagent concentrations and thermocycler conditions varied between primer sets (see ESM Table S1 for methods). Because the forward primer for locus B2Sym17 (B2Sym17F1: 5'-CGA TGG AGG CAT ACA AGT GA-3') failed to amplify some samples, an alternative forward primer was used (B2Sym17F2; Leydet and Hellberg 2016). Amplicons were visualized on

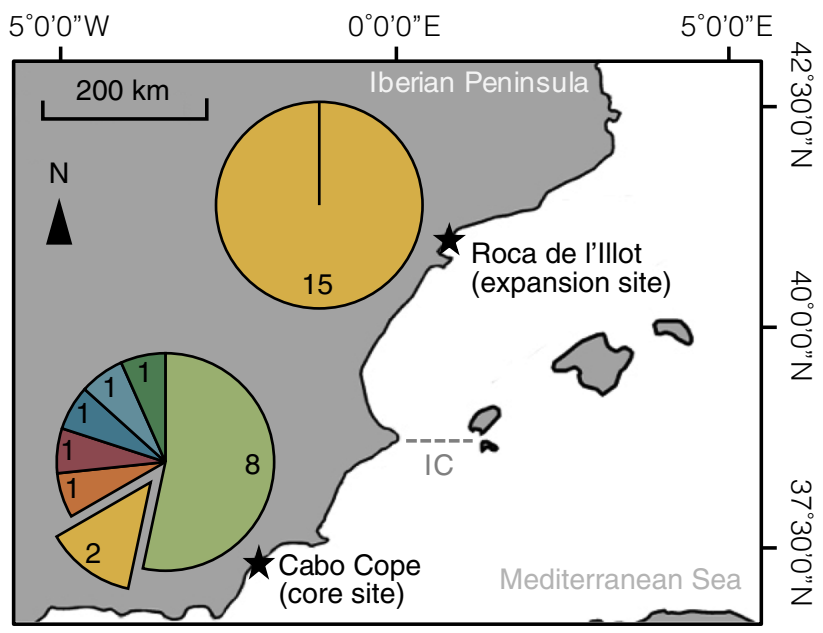

Fig. 1 Symbiodinium psygmophilum multilocus genotype diversity (MLG; based on four microsatellite loci) in a core (Cabo Cope) and expansion front (Roca de l'Illot) Oculina patagonica population. Unique MLGs are indicated in different colors, and the number of host colonies harboring a specific $S$. psygmophilum MLG is printed within. IC Ibiza Channel 
polyacrylamide gels as described by Santos et al. (2003a). Fragments amplified using primer set B2Sym14 had variable sizes in the northern and eastern Mediterranean, but not at the two Iberian sites; therefore, this locus was not included during the assignment of multilocus genotypes (MLGs) for the latter two sites. Furthermore, Iberian samples that failed to amplify at one or several of the microsatellite loci were excluded (final $n=30,15$ per Iberian site). Linkage disequilibrium was tested at Cabo Cope to verify that the loci were independent (ESM Table S2). Lastly, remote sensing data for temperature, photosynthetically active radiation (PAR), and concentrations of chlorophyll $a$, phosphate and inorganic nitrogen were obtained for both Iberian study sites (ESM Table S3).

\section{Results and discussion}

Analysis of cp23S fragments verified that all samples contained S. psygmophilum (Santos et al. 2003a). The primer pairs reported here consistently amplified polymorphic alleles that differ within the western North Atlantic and the Mediterranean Sea, providing a useful tool for studying population differentiation in S. psygmophilum. All five microsatellite loci were polymorphic in at least one location (ESM Table S4). The western Atlantic host population harbored a diverse set of symbionts, reflecting Leydet and Hellberg (2016). Using our five microsatellite loci, we identified at least 12 MLGs across these populations $(n=19$; Table 2). Multiple alleles were found at locus B2Sym17 in two Oculina spp. samples from Cape Florida, indicating the presence of multiple Symbiodinium genotypes within these colonies. No fragments were visualized for several samples screened with loci B2Sym14 and
B2Sym17 (10 and 11, respectively) from Cape Florida, Daytona Beach and North Carolina. Direct sequencing using the B2Sym 17 primers, however, resulted in detection of these alleles (Leydet and Hellberg 2016). We found seven unique MLGs within samples from the northern and eastern Mediterranean Sea (excluding Iberian sites; Table 2).

Within the Iberian sites, we identified seven unique MLGs at the core host population based on size variation at four microsatellite loci (B2Sym02, B2Sym04, B2Sym17 and Gv2_100). A single MLG was present in all $O$. patagonica individuals sampled at the expansion population and was shared with two individuals from the core population (Fig. 1). None of the microsatellite loci showed significant deviation from linkage equilibrium (ESM Table S2).

Several possible scenarios may explain reduced symbiont genotype diversity at the expansion front. First, because $O$. patagonica can propagate by means of polyp expulsion (Kramarsky-Winter et al. 1997), high rates of symbiont clonality within a coral population can be caused by asexual host propagation whereby host "offspring" maintain the "parental" symbiont genotypes. However, no $O$. patagonica clones were observed during a recent survey using the same samples from our expansion front study site, suggesting that asexual reproduction is not a major mechanism of propagation (Leydet 2016).

Since recruits acquire compatible Symbiodinium from the environment (Fine et al. 2001), migrating larvae or newly settled recruits in the expansion area must have acquired symbionts locally, i.e., at the expansion front. This suggests several not mutually exclusive possibilities: (1) the environmental pool has low $S$. psygmophilum diversity due to limited connectivity or a founder effect; (2)
Table 1 Sequences of forward (F) and reverse (R) primer sets for each microsatellite locus

\begin{tabular}{ll}
\hline Locus & Primer sequence $\left(5^{\prime}-3^{\prime}\right)$ \\
\hline B2Sym02 & F: CTC CAT GTG CAA AGG GAA TC \\
& R: ATG GTG CTT TGT TCA GAC CC \\
B2Sym04 & F: AGC CAA ACC GTG AAA CAA CT \\
& R: CCT GTC AGA GTT TGC CAC AA \\
B2Sym14 & F: GCA CTC TAT CCA CAG CAC CA \\
& R: GCA TGA TAG GCA CTT GAG CA \\
B2Sym17 & F2 ${ }^{\text {a }}$ GCA ACA ATC ATA TTG ACT AGG CC \\
& R: GAT CCT ATT GGT GGT GGT GG \\
GV2_100 & F: CTA TCA AGG TCC TAT TTT CAC AGC ACA A \\
& R: A CAG GCG AGG TAT AGT ATT GAG TAA AAG AA
\end{tabular}

Reagent concentrations, thermocycler conditions, and motif sequences can be found in ESM Table S1. Size ranges per area are given in ESM Table S4

${ }^{a}$ Forward primer F2 was designed by Leydet and Hellberg (2016). The F1 primer sequence is presented in the text

b Gv2_100 forward and reverse primers were designed by Andras et al. (2009) for Symbiodinium B1 
Table 2 Sample sizes $(n)$ and number of Symbiodinium psygmophilum multilocus genotypes (MLGs) identified at each site based on four (Iberian study sites) or five (all other sites) microsatellite loci

\begin{tabular}{lcl}
\hline Site & $n$ & No. of MLGs \\
\hline Panama City & 5 & 3 \\
Cape Florida & 4 & 4 \\
Daytona Beach & 5 & 4 \\
North Carolina & 5 & 4 \\
Greece & 2 & 2 \\
Israel & 2 & 2 \\
Lebanon & 2 & 2 \\
Italy & 2 & 1 \\
Cabo Cope & 15 & 7 \\
Roca de l'Illot & 15 & 1
\end{tabular}

Genotypes were only shared between the core (Cabo Cope) and expansion (Roca de l'Illot) Iberian study sites

local selective pressures limit Symbiodinium diversity in the environmental pool; and/or (3) selection by the host and/or environment for specific symbiont pairings has resulted in local dominance of a single symbiont MLG.

Although symbiont species such as $S$. psygmophilum can have a broad distribution at the species level (LaJeunesse et al. 2012, 2014), dispersal of symbionts at the population level is generally thought to be limited (see review by Thornhill et al. 2017). Moreover, observations between 1992 and 2010 suggest that northward expansion of $O$. patagonica has occurred through a small number of longdistance dispersal events (between 76 and $182 \mathrm{~km}$; Serrano et al. 2013), possibly limited by the oceanographic barrier represented by the Ibiza Channel (Fig. 1; Leydet 2016), and symbiont dispersal may have been similarly low. Subsequently, the most prevalent symbiont strains in the environment might be those that are released by nearby adult colonies (Nitschke et al. 2016), leading to dominance of a single symbiont MLG. However, two other cnidarians native to the expansion front (Cladocora caespitosa and Bunodeopsis strumosa) have been recorded to harbor $S$. psygmophilum in addition to clade A symbionts at several locations in the western Mediterranean Sea (reviewed by Casado-Amezúa et al. 2016), indicating that there are several putative sources of Symbiodinium at the expansion front. Therefore, environmental symbiont diversity here may not be shaped solely by limited dispersal rates.

Alternatively, given that unique genotypes within $S$. psygmophilum may exhibit functional variation (Parkinson et al. 2016), some of these genotypes might fare better under environmental conditions at the expansion front, potentially leading to limited diversity within the environmental pool (Pettay and LaJeunesse 2013; Baums et al.
2014). Similarly, the observed pattern of reduced symbiont genetic variation may be a result of predominant association of coral hosts with a distinct symbiont genotype well adapted to the prevailing local environment (e.g., Hume et al. 2016). Coral-associated symbiont distributions have been proposed to correlate with several environmental parameters including depth (LaJeunesse 2002; Kirk et al. 2009), PAR (Rowan et al. 1997) and temperature (Baums et al. 2014; LaJeunesse et al. 2014; Hume et al. 2016). While sampling depths were similar between the two populations, satellite data indicate that the expansion front site experienced lower yearly mean and minimum temperatures and lower mean PAR than the core population but higher concentrations of chlorophyll $a$ and nutrients (phosphate, inorganic nitrogen; ESM Table S3). Low winter temperatures at the expansion site have been related to recurring patterns of partial colony mortality and subsequent tissue regeneration, which is energetically costly (Serrano et al. 2017). Therefore, local conditions may exert selective pressure on the environmental Symbiodinium pool and/or on host-symbiont associations.

In summary, our findings suggest that $O$. patagonica range expansion is accompanied by reduced genetic diversity of Symbiodinium, and this may be caused either by low diversity in the environmental pool, environmental selection of symbionts and/or selection for specific hostsymbiont pairings. However, a more detailed genetic characterization of $S$. psygmophilum along the Iberian Peninsula using these new primer sets is needed to determine the most likely driver of the observed reduction in genetic diversity.

Acknowledgements Financial support was provided by the Spanish Government Project CGL2013-43106-R, the Marine Biogeochemistry and Global Change Research Group from "Generalitat de Catalunya" (2014SGR 1029) (RC and MR) and NSF-OCE-09-26822 (MAC).

Open Access This article is distributed under the terms of the Creative Commons Attribution 4.0 International License (http://crea tivecommons.org/licenses/by/4.0/), which permits unrestricted use, distribution, and reproduction in any medium, provided you give appropriate credit to the original author(s) and the source, provide a link to the Creative Commons license, and indicate if changes were made.

\section{References}

Andras JP, Kirk NL, Coffroth MA, Harvell CD (2009) Isolation and characterization of micosatellite loci in Symbiodinium B1/B184, the dinoflagellate symbiont of the Caribbean sea fan coral, Gorgonia ventalina. Mol Ecol Resour 9:989-993

Baskett ML, Gaines SD, Nisbet RM (2009) Symbiont diversity may help coral reefs survive moderate climate change. Ecol Appl 19:3-17

Baums IB, Devlin-Durante MK, LaJeunesse TC (2014) New insights into the dynamics between reef corals and their associated 
dinoflagellate endosymbionts from population genetic studies. Mol Ecol 23:4203-4215

Casado-Amezúa P, Terrón-Sigler A, Pinzón JH, Furla P, Forcioli D, Allemand D, Ribes M, Coma R (2016) General ecological aspects of anthozoan-Symbiodinium interactions in the Mediterranean Sea. In: Goffredo S, Dubinsky Z (eds) The cnidaria, past, present and future: the world of medusa and her sisters. Springer, Switzerland, pp 375-386

Coffroth MA, Lasker HR, Diamond ME, Bruenn JA, Bermingham E (1992) DNA fingerprints of a gorgonian coral: a method for detecting clonal structure in a vegetative species. Mar Biol 114:317-325

Eytan RI, Hayes M, Arbour-Reily P, Miller M, Hellberg ME (2009) Nuclear sequences reveal mid-range isolation of an imperilled deep-water coral population. Mol Ecol 18:2375-2389

Fine M, Zibrowius H, Loya Y (2001) Oculina patagonica: a nonlessepsian scleractinian coral invading the Mediterranean Sea. Mar Biol 138:1195-1203

Hume BCC, Voolstra CR, Arif C, D’Angelo C, Burt JA, Eyal G, Loya Y, Wiedenmann J (2016) Ancestral genetic diversity associated with the rapid spread of stress-tolerant coral symbionts in response to Holocene climate change. Proc Natl Acad Sci U S A 113:4416-4421

Kirk NL, Andras JP, Harvell CD, Santos SR, Coffroth MA (2009) Population structure of Symbiodinium sp. associated with the common sea fan, Gorgonia ventalina, in the Florida Keys across distance, depth, and time. Mar Biol 156:1609-1623

Kramarsky-Winter E, Fine M, Loya Y (1997) Coral polyp expulsion. Nature 387:137

Kofler R, Schlötterer C, Lelley T (2007) SciRoKo: a new tool for whole genome microsatellite search and investigation. Bioinformatics 23:1683-1685

Koressaar T, Remm M (2007) Enhancements and modifications of primer design program Primer3. Bioinformatics 23:1289-1291

LaJeunesse TC (2002) Diversity and community structure of symbiotic dinoflagellates from Caribbean coral reefs. Mar Biol 141:387-400

LaJeunesse TC, Parkinson JE, Reimer JD (2012) A genetics-based description of Symbiodinium minutum sp. nov. and S. psygmophilum sp. nov. (Dinophyceae), two dinoflagellates symbiotic with cnidaria. J Phycol 48:1380-1391

LaJeunesse TC, Wham DC, Pettay DT, Parkinson JE, Keshavmurthy S, Chen CA (2014) Ecologically differentiated, stress tolerant endosymbionts in the dinoflagellate genus Symbiodinium (Dynophyceae) Clade D are different species. Phycologia 53:305-319

Leydet KP (2016) Phylogeography of Oculina corals and their algal symbionts: insights into the origin and expansion of Oculina patagonica in the Mediterranean. Ph.D. thesis, Louisiana State University, Baton Rouge, LA, 118 p

Leydet KP, Hellberg ME (2015) The invasive coral Oculina patagonica has not been recently introduced to the Mediterranean from the western Atlantic. BMC Evol Biol 15:79

Leydet KP, Hellberg ME (2016) Discordant coral-symbiont structuring: factors shaping geographical variation of Symbiodinium communities in a facultative zooxanthellate coral genus, Oculina. Coral Reefs 35:583-595

Muir PR, Wallace CC, Done T, Aguirre JD (2015) Limited scope for latitudinal extension of reef corals. Science 348:1135-1138
Nitschke MR, Davy SK, Ward S (2016) Horizontal transmission of Symbiodinium cells between adult and juvenile corals is aided by benthic sediment. Coral Reefs 35:335-344

Parkinson JE, Baumgarten S, Michell CT, Baums IB, LaJeunesse TC, Voolstra CR (2016) Gene expression variation resolves species and individual strains among coral-associated dinoflagellates within the genus Symbiodinium. Genome Biol Evol 8:665-680

Pettay DT, LaJeunesse TC (2007) Microsatellites from clade B Symbiodinium spp. specialized for Caribbean corals in the genus Madracis. Mol Ecol Notes 7:1271-1274

Pettay DT, LaJeunesse TC (2013) Long-range dispersal and highlatitude environments influence the population structure of a "stress-tolerant" dinoflagellate endosymbiont. PLoS One 8:e79208

Precht WF, Aronson RB (2004) Climate flickers and range shifts of reef corals. Front Ecol Environ 2:307-314

Rowan R, Knowlton N, Baker A, Jara J (1997) Landscape ecology of algal symbionts creates variation in episodes of coral bleaching. Nature 388:265-269

Santos SR, Gutiérrez-Rodríguez C, Coffroth MA (2003a) Phylogenetic identification of symbiotic dinoflagellates via length heteroplasmy in domain $\mathrm{V}$ of chloroplast large subunit (cp23S)_ribosomal DNA sequences. Mar Biotechnol 5:130-140

Santos SR, Gutiérrez-Rodríguez C, Lasker HR, Coffroth MA (2003b) Symbiodinium sp. associations in the gorgonian Pseudopterorgia elisabethae in the Bahamas: high levels of genetic variability and population structure in symbiotic dinoflagellates. Mar Biol 143:111-120

Serrano E, Ribes M, Coma R (2017) Recurrent partial mortality events in winter shape the dynamics of the zooxanthellate coral Oculina patagonica at high latitude in the Mediterranean. Coral Reefs 36:27-38

Serrano E, Coma R, Ribes M, Weitzmann B, García M, Ballesteros E (2013) Rapid northward spread of a zooxanthellate coral enhanced by artificial structures and sea warming in the western Mediterranean. PLoS One 8:e52739

Silverstein RN, Cunning R, Baker AC (2015) Change in algal symbiont communities after bleaching, not prior heat exposure, increases heat tolerance of reef corals. Glob Chang Biol 21:236-249

Thornhill DJ, Kemp DW, Bruns BU, Fitt WK, Schmidt GW (2008) Correspondence between cold tolerance and temperate biogeography in a Western Atlantic Symbiodinium (Dinophyta) lineage. J Phycol 44:1126-1135

Thornhill DJ, Howells EJ, Wham DC, Steury TD, Santos SR (2017) Population genetics of reef coral endosymbionts (Symbiodinium, Dinophyceae). Mol Ecol. doi: 10.1111/mec.14055

Untergasser A, Cutcutache I, Koressaar T, Ye J, Faircloth BC, Remm M, Rozen SG (2012) Primer3-new capabilities and interfaces. Nucleic Acids Res 40:e115

Wilkinson CR (2008) Status of coral reefs of the world: 2008. Global Coral Reef Monitoring Network and Australian Institute of Marine Sciences, Townsville

Zibrowius H, Ramos AA (1983) Oculina patagonica, scléractiniaire exotique en Méditerranée-nouvelles observations dans le SudEst de l'Espagne. Rapports Commission Internationale pour l'Exploration Scientifique de la Mer Méditerranée 28:297-301 